\title{
Vaginal and oral nitrimidazine in the treatment of vaginal trichomoniasis
}

\author{
S. M. ROSS \\ Department of Obstetrics and Gynaecology, Princess Tsahai Hospital, P.O. Box 1377, Addis Ababa, Ethiopia
}

Since its introduction 12 years ago metronidazole has almost totally replaced the plethora of therapeutic agents previously employed in the treatment of trichomoniasis. Evans and Catterall (1971) suggest that metronidazole approaches the therapeutic ideal; nevertheless, when used according to the standard regime of $200 \mathrm{mg}$. three times a day for 7 days a cure rate as low as 61 per cent. has been reported (Aure and Gjønnaess, 1961) and there is superinfection with Candida albicans in a significant number of cases. Cantone and ten others (1969) synthesized and investigated a new nitroimidazole compound, nitrimidazine ${ }^{\star}$, which has theoretical advantages over metronidazole in that, after similar dosage, levels of active substances can be detected in the blood which are slightly higher than those obtainable with metronidazole (de Carneri, 1969). Furthermore, the urinary metabolites of nitrimidazine are also active against the trichomonad whereas those of metronidazole are not (de Carneri and 11 others, 1969). In contrast to metronidazole, nitrimidazine is well absorbed by the vaginal wall and is found in the blood and urine after topical administration (de Carneri, 1969).

Clinical trials of nitrimidazine using a single oral dose of $2 \mathrm{~g}$. are reported below. The drug was also supplied as a vaginal preparation combined with nystatin 100,000 i.u. and tetracycline base equivalent to $100 \mathrm{mg}$. tetracycline $\mathrm{HCl}$ and three further clinical trials with this preparation are described.

\section{Patients and methods}

The trials were carried out on 142 pregnant women and 115 gynaecological patients attending the antenatal and gynaecological clinics at the Princess Tsahai Memorial Hospital, and the Lideta Maternal and Child Health Centre, Addis Ababa. The schemes of treatment with pessaries of nitrimidazine, nystatin, and tetracycline and $250 \mathrm{mg}$. tablets of nitrimidazine are shown in Table I. Once it became apparent that a course of treatment was not achieving a satisfactory cure rate, that particular trial was abandoned. Diagnosis was made by immersing a cotton-wool swab in the secretion in the posterior vaginal fornix and transferring it to a test tube containing about $1 \mathrm{ml}$. normal saline. A suspension of this discharge was
TABLE I No. of patients and schemes of treatment

\begin{tabular}{llll}
\hline Group & $\begin{array}{l}\text { No. of } \\
\text { patients }\end{array}$ & $\begin{array}{l}\text { No. of } \\
\text { pessaries }\end{array}$ & $\begin{array}{l}\text { No. of } 250 \mathrm{mg} . \\
\text { tablets }\end{array}$ \\
\cline { 2 - 3 } & 21 & 6 & - \\
A & 37 & 12 & - \\
C & 53 & 18 & - \\
D & 88 & - & 8 stat \\
E & 58 & - & $\begin{array}{l}8 \text { stat to } \\
\text { patient and } \\
\text { consort }\end{array}$ \\
\end{tabular}

ane inserted each night

examined at once under the low power microscope objective. A smear was also made for Gram-staining.

Analysis of the group studied according to age and marital status is shown in Table II. In each group most of the patients were between 20 and 29 years of age; 63 were either unmarried, divorced, separated, or widowed. The consort was not treated except in Group F, but coitus was advised against between the initial treatment and first follow-up.

TABLE II Age and marital status

\begin{tabular}{|c|c|c|c|c|c|c|}
\hline \multirow{2}{*}{ Group } & \multicolumn{4}{|c|}{ Age group } & \multicolumn{2}{|c|}{ Marital status } \\
\hline & $0-19$ & $20-29$ & $30-39$ & 39 & Married & Single \\
\hline $\begin{array}{l}\text { A } \\
\text { B } \\
\text { C } \\
\text { D } \\
\text { E }\end{array}$ & $\begin{array}{r}6 \\
3 \\
4 \\
19 \\
10\end{array}$ & $\begin{array}{l}11 \\
24 \\
32 \\
45 \\
37\end{array}$ & $\begin{array}{r}4 \\
8 \\
16 \\
21 \\
9\end{array}$ & $\begin{array}{r}- \\
2 \\
1 \\
3 \\
2\end{array}$ & $\begin{array}{l}15 \\
31 \\
39 \\
56 \\
53\end{array}$ & $\begin{array}{r}6 \\
6 \\
14 \\
32 \\
5\end{array}$ \\
\hline
\end{tabular}

Vaginal discharge was the commonest symptom in all groups, followed by vulval irritation, dysuria, and dyspareunia in that order. The amount of discharge was assessed objectively and the groups were similar in this respect. There was very little correlation between the number of trichomonads, the amount of discharge, and the appearance of the vaginal epithelium.

The follow-up procedure aimed at re-examining each patient within 1 week of completing treatment by the same methods as described for the initial examination. Patients were asked to attend for further follow-up tests for a period of 12 weeks after the completion of treatment.

\section{Results}

There were a total of 24 defaulters spread fairly evenly over the five groups (Table III). Of the remaining 233 patients the percentage who could be considered 
cured on the basis of one or more follow-up tests varied from 30 per cent. in Group A to 96 per cent. in Group E (Tables III, IV, V). Five cases with very abundant trichomonads were in hospital at the time of treatment with $2 \mathrm{~g}$. nitrimidazine, and the disappearance of active trichomonads in these cases was dramatic-none were visible 12 hours later.

TABLE III Tests of cure

\begin{tabular}{|c|c|c|c|c|c|c|c|}
\hline \multirow{2}{*}{ Group } & \multicolumn{5}{|c|}{$\begin{array}{l}\text { No. of negative } \\
\text { examinations }\end{array}$} & \multicolumn{2}{|l|}{ Patients } \\
\hline & 1 & 2 & 3 & 4 & 5 & Defaulting & Cured \\
\hline A & 1 & 5 & - & - & - & 1 & 6 \\
\hline B & 5 & 3 & 2 & 4 & 4 & 6 & 18 \\
\hline $\mathrm{C}$ & 9 & 10 & 8 & 3 & 2 & 2 & 32 \\
\hline D & 23 & 16 & 13 & 11 & 7 & 12 & 70 \\
\hline $\mathrm{E}$ & 15 & 14 & 10 & 9 & 5 & 3 & 53 \\
\hline
\end{tabular}

a Over a period of 12 weeks

TABLE V Overall results of treatment

\begin{tabular}{|c|c|c|c|c|}
\hline \multirow{2}{*}{ Group } & \multirow{2}{*}{ No. treated } & \multirow{2}{*}{ No. followed } & \multicolumn{2}{|c|}{ Patients cured } \\
\hline & & & No. & $\begin{array}{l}\text { Per cent. of } \\
\text { those followed }\end{array}$ \\
\hline A & 21 & 20 & 6 & 30 \\
\hline B & 37 & 31 & 18 & 58 \\
\hline C & 53 & 51 & 32 & 63 \\
\hline D & 88 & 76 & 70 & 92 \\
\hline $\mathrm{E}$ & 58 & 55 & 53 & 96 \\
\hline
\end{tabular}

C. albicans was seen at the initial examination in 18 cases; after treatment of the trichomonas infection, it was found in 46 cases (Table IV). The candidiasis was not treated unless it appeared to be producing symptoms, and this only arose when the patients were receiving oral nitrimidazine.
Gram-negative intracellular diplococci were seen on only four occasions but Gram-negative extracellular diplococci were identified in 108 cases. It is likely that if culture and fermentation tests had been available a considerable number of cases of gonorrhoea would have been found.

The 142 pregnant women were treated at periods of gestation varying from 10 weeks to term (Table VI). Fifty pregnancies have so far been followed up to completion. One patient, an unmarried deaf mute, aborted 2 weeks after taking eight nitrimidazine tablets orally at 13 weeks gestation. One primigravid patient had a fresh stillbirth 1 month after oral nitrimidazine, after a breech delivery. In the case of the missed abortion and the intrauterine death the pregnancy was already doomed before treatment was given. The remaining 46 full-term infants were all examined clinically between birth and the age of 3 months and no abnormality was found.

The incidence of side-effects appears to be rather high (Table VII, overleaf). This could be because patients were asked direct questions concerning each likely complication. Two patients discontinued vaginal treatment because of a sensation of severe burning in the vagina. Those who vomited after the oral treatment were either re-treated successfully or were judged to have vomited sufficiently long after the administration of the drug for most of it to have been absorbed.

\section{Discussion}

The mute testimony of hundreds of discarded methods of treatment (Trussell, 1947) is evidence of the difficulties which have arisen in vaginal treatment of

TABLE IV Treatment failures and occurrence of candidiasis

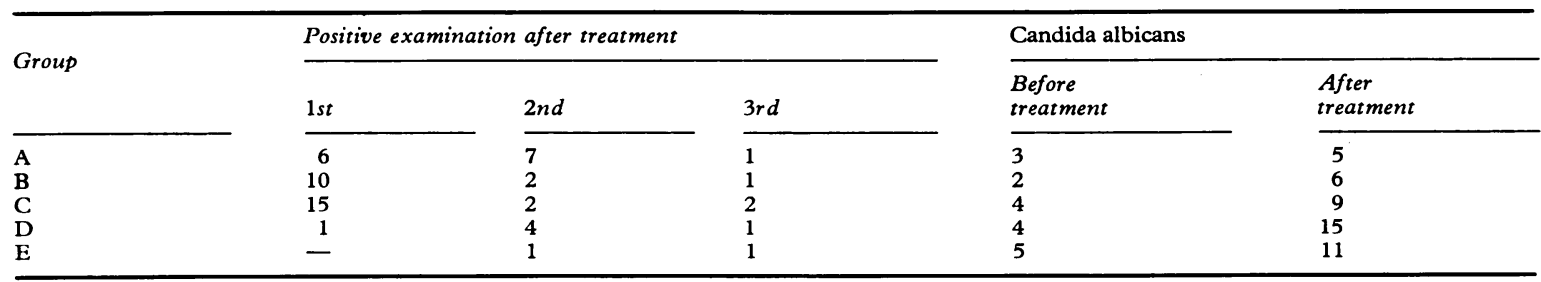

TABLE VI Length of gestation and outcome (where known)

\begin{tabular}{|c|c|c|c|c|c|c|}
\hline Group & 1 st trimester & No. infants seen & 2nd trimester & No. infants seen & $3 r d$ trimester & No. infants seen \\
\hline A & 5 & 2 & 5 & 1 & 9 & 2 \\
\hline $\mathbf{B}$ & 5 & - & 8 & 3 & 12 & 6 \\
\hline C & 4 & - & 14 & 5 & 15 & 6 \\
\hline D & - & - & 7 & $\begin{aligned} 5 & (1-\mathbf{A} / \mathbf{B}) \\
& (1-\text { missed } \mathbf{A} / \mathbf{B})\end{aligned}$ & 35 & $\begin{array}{c}15 \text { (1-I.U.D.) } \\
\text { (1-S.B.) }\end{array}$ \\
\hline E & 1 & 一 & 7 & 2 & 15 & 3 \\
\hline
\end{tabular}

A/B = abortion $\quad$ I.U.D. = intrauterine death $\quad$ S.B. = still birth


TABLE VII Side-effects

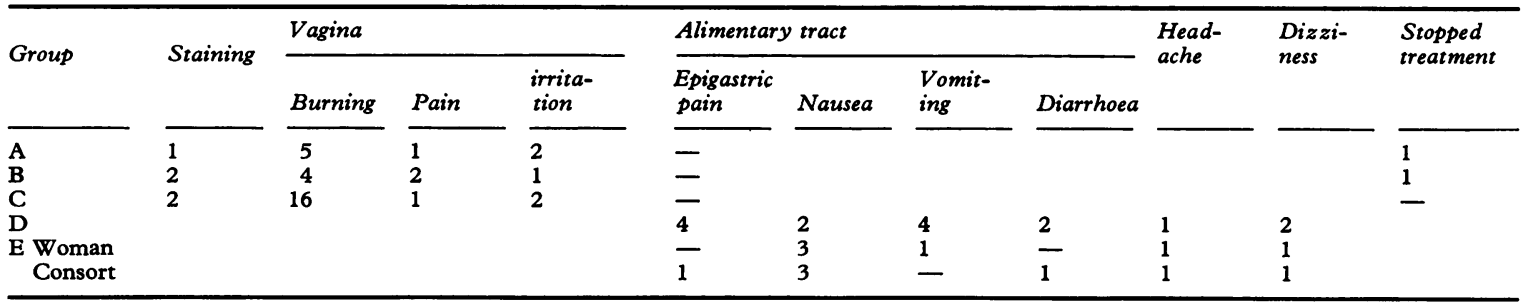

trichomoniasis. Urethral parasitism, involvement of para-urethral and Bartholin glands as well as the deep crypts of the vaginal lining all provide foci where the protozoon can lurk undisturbed by topical agents. Thus, to be effective, a topical agent must also be absorbed. The combination of nitrimidazine with the broad-spectrum antibiotic tetracycline and with the fungicidal agent nystatin should provide a compound pessary active against the trichomonad, pathogenic mycetes, and many Gram-negative and Gram-positive bacteria. The results presented here suggest that even an 18-day pessary course is insufficient. However, anything longer than this is likely to prove very tedious for the patient, who will often discontinue treatment as soon as she is symptomatically improved. This is likely to be well before the trichomonads are eliminated from the vagina since it was found that 90 per cent. of the patients given only six pessaries had marked symptomatic improvement but only 30 per cent. were cured Emanueli and de Carneri (1969) report a 96 per cent. cure rate after treatment $w^{\text {th }}$ then pessaries but these cases were not followed up beyond the first posttreatment examination.

The fact that the results in Group C (18 pessaries) were not significantly better than in Group B (12 pessaries) could well be due to a better follow-up in Group C. Studies in Addis Ababa on other drugs claimed to be active against both Trichomonas vaginalis and Candida albicans do not give better results. Thus vaginal 'Floraquin' in a trial with a very limited follow-up cured 72 per cent. of patients (Ross and Akalu, 1971) and nifuratel given vaginally to the women and orally to both the patient and her consort achieved only a 30 per cent. cure rate.

Excellent results were obtained when nitrimidazine was given in a single dose of $2 \mathrm{~g}$. The cure rate of 92 per cent. found when the woman only was treated would have been even higher if the three patients who admitted the possibility of re-infection had been excluded. The 96 per cent. cure rate obtained when both the woman and her partner were treated is unusually high but in spite of lack of cultures is likely to be correct, as the majority of patients had more than one examination after treatment. The two treatment failures in this group are of interest. One patient was re-treated with a single dose of $2 \mathrm{~g}$. nitrimidazine and remains free of infection 2 months later. The other was likely to have been re-infected since it was subsequently discovered that her husband had failed to take his treatment. The incidence of side-effects ( 17 per cent.) in Groups D and E is double that reported for the standard course of nitrimidazine (Emanuel and de Carneri, 1969), but none of the patients nor their partners suffered more than minor inconvenience. Many appreciated the uncomplicated course of treatment.

Studies carried out on rats and rabbits indicate that nitrimidazine does not interfere with embryofoetal organogenesis (Cantone and 10 others, 1969), and toxic effects on adult humans have not been described. It therefore seems unreasonable to withold the drug from pregnant women after the first 10 weeks of pregnancy. 130 pregnant women were treated by Oliveira and Lima (1970) and no harmful effects were discovered. In the present series there were no adverse effects on the mother or the infant in 46 of the fifty pregnancies so far followed-up. The two stillbirths and one of the abortions reported here were not related to the use of nitrimidazine and the second abortion is most unlikely to have been.

Superinfection with Candida albicans was a probem as it is with any patients given effective treatment for trichomoniasis, but this is no more of a problem with oral nitrimidazine than it is with metronidazole.

\section{Summary}

Nitrimidazine combined with tetracycline and nystatin was administered vaginally to 111 women with Trichomonas vaginalis infection. Three different treatment schedules were used. The most effective was a course of eighteen pessaries (one each night) which gave a cure rate of 63 per cent. among the 51 followed.

Nitrimidazine was also given orally to 146 women. 88 were given a single dose of $2 \mathrm{~g}$. 58 were treated with their sex partners, each receiving a single $2 \mathrm{~g}$. 
dose. The cure rates were 92 and 96 per cent. respectively, and there were no serious side-effects.

Nitrimidazine compound pessaries have little to commend them except in situations where facilities for accurate diagnosis are not available. Oral nitrimidazine in a single $2 \mathrm{~g}$. dose is very effective in the treatment of vaginal trichomoniasis and the ease of treatment is most acceptable to the patient.

\section{References}

Aure, J. C., and GJønnaess, H. (1969) Acta obstet. gynec. scand., 48, 440

Cantone, A., de Carneri, I., Emanueli, A., Giraldi, P. N., Logemann, W., Longo, R., Meinardi, G., Monti, G., Nannini, G., Tosolini, G., and Vita, G. (1969) G. Mal. infett., 21, 954

De CARNERI, I. (1969) Artzneimittel-Forsch., 19, 382

-, Cantone, A., Emanueli, A., Giraldi, P. N., Logemann, W., Longo, R., Meinardi, G., Monti, G., Nannini, G., Tosolini, G., and Vita, G. (1969) VI int. Congr. Chemother., Tokyo

Emanueli, A., and de Carneri, I. (1969) VI int. Congr. Chemother., Tokyo

Evans, B. A., and Catterall, R. D. (1971) Brit. med. F., 4, 146

Oliveira, F. C., and Lima, R. T. (1970) Hospital (Rio de $\mathcal{F}$.), 78, 561
Ross, S. M., and AKalu, T. (1971) Ethiop. med. F., 9, 141

TRUSSELL, R. E. (1947) 'Trichomonas vaginalis and Trichomoniasis', pp. 149-220. Thomas, Springfield, Ill.

Traitement de la vaginite à trichomonas par la nitrimidazine vaginale et buccale

SOMMAIRE

On a administré, par voie vaginale, de la nitrimidazine associée à la tetracycline et à la nystatine à 111 femmes infectées de Trichomonas vaginalis. Trois schémas thérapeutiques différents furent utilisés. Le plus efficace fut une série de 18 comprimés vaginaux (un chaque nuit) qui donne un taux de guérison de 63 pour cent pour les 51 cas suivis.

La nitrimidazine fut aussi prescrite par voie buccale à 146 femmes. 88 reçurent une dose unique de $2 \mathrm{~g} ; 58$ furent traitées en même tempts que leurs partenaires qui recevaient chacun une dose unique de $2 \mathrm{~g}$. Les taux de guérison furent, respectivement, de 92 et 96 pour cent. Il n'y eut aucun effet secondaire sérieux.

Les comprimés mixtes de nitrimidazine ne sont que modérément recommandés, sauf dans les cas où l'on ne dispose pas de facilités pour un diagnostic convenable. La nitrimidazine par voie buccale à dose unique de $2 \mathrm{~g}$ est très efficace dans le traitement de la trichomonase vaginale et la facilité du traitement rend celui-ci particulièrement bien accepté par la malade. 